\title{
Memory and the extensor phase of convulsions induced by electroconvulsive shock'
}

RALPH R. MILLER and NORMAN E. SPEAR, Rutgers University, New Brunswick, N.J.08903

In Experiment 1, rats receiving electroconvulsive shock immediately following one-trial passive avoidance training displayed less amnesia on a 24-h retention test when the convulsion lacked a phase of hindlimb tonic extension. Experintent 2 found that attenuated amnesia and incomplete convulsions following electroconvulsive shock occurred in fewer animals on deprivation than on ad lib diets. However, deprivation did not appear to affect degree of amnesia in those animals exhibiting complete grand mal convulsions. These results suggest that future ECS research on mernory can circumvent the problem of incomplete convulsions by using either young animals or adults on weightlimiting diets.

In recent years, electroconvulsive shock (ECS) has become a common tool with which to study memory processes. Despite the use of constant current, most ECS experiments find that in the seconds immediately following current offset a percentage of animals fail to exhibit hindlimb tonic extension prior to entering the almost inevitable clonic phase of convulsion. The frequency of complete grand mal convulsions increases with increasing current but asymptotes at some fractional level, approximately $90 \%$ for albino rats administered ECS through saline moistened earclips (e.g., Weissman, 1963) Weissman (1963) and, in a somewhat different situation, Experiment 1 of the present study, found less than normal degrees of retrograde amnesia (RA) to accompany clinic-only convulsions. This differential effect on performance, reflecting perhaps nonmemory as well as memory processes, indicates the importance of understanding the unique characteristics of animals failing to yield full tonic-clonic convulsions.

\section{EXPERIMENT 1 Method}

The Ss were 60 naive male albino Sprague-Dawley (Madison, Wisc.) rats. They and the procedure of this experiment were originally part of another larger study that was terminated due to an unusually high occurrence of partial convulsions. Each animal was 65 days old and weighed 240-280 g on Day 1 of the experiment. The Ss were maintained on ad lib water and
Purina rat chow and were quartered in perpetually illuminated individual cages. Two Ss paralyzed after ECS were discarded and replaced with other $S s$ of the same description. Both discarded Ss displayed clonic-only convulsions.

One-trial passive avoidance training was accomplished in a stepdown apparatus which consisted of a $4 \times 6 \frac{1}{2}$-in. platform centered $3 \frac{1}{2}$ in. over a $20 \times 20$-in. grid floor. A Grason-Stadler scrambled shock source set at $1.6 \mathrm{~mA}$ was used to deliver a $5-\mathrm{sec}$ footshock (FS) through the grid floor. Earclips, worn on all trials, were suspended over the apparatus and served to administer a 60-rms-mA .5-sec ECS. The suspending wires were attached to a counterweight designed to permit the animal maximal freedom of motion.

On Days 1-3, each animal received two 2-min earclip adaptation trials in the home cage, trials being separated by $2-h$ intervals. On Day 4 , Ss were given three pretraining trials and one training trial, trials being spaced $2 \mathrm{~h}$ apart. The pretraining trials were included in the paradigm in order to establish a uniformly low operant stepdown latency. Each such trial consisted of placing $S$ on the platform with earclips attached and waiting for the animal to step down; a criterion of four paws on the floor was used. Five seconds after reaching the floor, the trial was terminated. On the training trial, Ss, wearing earclips, were again placed on the platform and stepdown latencies were recorded. Upon stepping down, Ss received a 5 -sec FS followed immediately by ECS. The sequence of the resultant convulsion was carefully observed. Before regaining consciousness, $\mathrm{S}$ was returned to the home cage Twenty-four hours later, each animal, wearing earclips, was returned to the platform for a retention trial on which a 300-sec latency upper limit was applied. All stepdown latencies were converted to logs to permit the use of parametric statistics. Results

One-half to $2 \mathrm{sec}$ after ECS termination, 12 Ss underwent partial hindlimb tonic extension (PT) in which the hindlegs formed angles to the body axis of between $15 \mathrm{deg}$ and 165 deg. This "hybrid" convulsion, not readily classifiable as either a complete grand mal or a clonic-only convulsion, is in contrast to the frequent assertion that tonic extension is an all-or-none property of a convulsion (e.g., Stern, McDonald, \& Werboff, 1957). Of the remaining $48 \mathrm{Ss}, 30$ produced full tonic-clonic convulsions ( $T$ ) with hindlegs $165 \mathrm{deg}$ or more behind $S$ and
18 underwent clonic-only convulsions (C).

All Ss had stepdown latencies of less than $8 \mathrm{sec}$ on the training trial and an overall $F$ test found this measure not to differ $(p>.20)$ as a function of the subsequent form of convulsion. However, animals displaying different convulsive patterns did differ in performance on the retention trial with median latencies of $18.1,41.7$, and $49.7 \mathrm{sec}$ for Groups T, PT, and C, respectively $(F=4.96, d f=2 / 57, p<.02)$. Notably, all three group medians were appreciably less than the FS-without-ECS control groups observed in this apparatus in other studies (e.g., Lewis, Miller, \& Misanin, 1968). The group differences in the present experiment apparently reflect differing degrees of amnesia rather than an all-or-none RA effect. Individual $t$ tests between all pairs of groups yielded a significant difference between the $T$ and $C$ groups $(\mathrm{t}=2.60, \mathrm{df}=46, \mathrm{p}<.02)$; no other $\mathrm{t}$ proved significant ( $\mathrm{ps}>.05$ ).

We conclude that amnesia correlated positively with the severity of the convulsion despite the constant-current ECS administered to all Ss. The term "correlated" is necessary because the convulsive sequence was not experimentally manipulated in Experiment 1.

\section{Discussion}

The correlation of memory retention with convulsive pattern is theoretically interesting but a methodological inconvenience. Three observations suggest an explanation of this correlation: (1) A positive correlation between occurrence of clonic-only convulsions and body weight has frequently been reported (e.g., Stern, McDonald, \& Werboff, 1957). This is consistent with the surprisingly high number of incomplete convulsions observed in the present study and the fact that Ss were $80.100 \mathrm{~g}$ heavier than the first author previously had used (e.g., Lewis, Miller, \& Misanin, 1968). (2) Degree of RA has been found to increase with ECS current level (e.g., Jarvik \& Kopp, 1967). (3) Weissman (1964) reported that at unusually high ECS levels (150 mA) some incomplete convulsions continued to occur but RA in these animals was as great as among full tonic-clonic Ss. Apparently RA increases with current even when Ss display only the clonic phase, but the curve is displaced down the RA axis from the animals exhibiting full convulsions. It is as if the amnestically effective current in the clonic-only $S$ is a fractional part of that in the complete grand mal S. Moreover, the clonic-only animal 
tends to weigh more than the full tonic-clonic animal.

Perhaps the additional body weight of the heavy $S$ reduces the effective current. This effective current may be assumed to be restricted to all or part of the current actually transversing the central nervous system. Due to the relatively high resistance of the skull encasing the brain and the low resistance of the extracranial tissue, a considerable proportion of the applied current is shunted around the brain rather than passing through it. Hays (1950) found this proportion to be approximately $80 \%$ in monkeys. An increase in body weight would decrease the resistance of the shunt without having a major effect upon the high resistance of the skull; hence, an even smaller percentage of the total current would transverse the brain of the fatter animal.

The observed correlations of body weight and retention with incomplete convulsions suggest that both the occurrence of incomplete convulsions and the frequency of Ss not demonstrating a normal post-ECS retention deficit could be controlled through manipulation of body weight. Experiment 2 of this study examines this hypothesis. McDonald (1960) varied body weight of rats and observed the convulsive response to 15 successive ECSs; the only statistic he reports is a positive correlation of .231. The present study included a measure of memory retention and, in keeping with current practice, each $S$ received only a single ECS.

\section{EXPERIMENT 2 Method}

The Ss were 60 naive male albino Sprague-Dawley (Madison, Wisc.) rats. On Day 1, each animal was 75 days old and weighed 295-345 g. For the duration of the study, 30 randomly chosen $S s$ were maintained on ad lib water and Purina rat chow (A). The other 30 Ss were main tained on ad lib water and $5 \mathrm{~g} /$ day of Purina rat chow given $1 \mathrm{~h}$ after handling on experimental days (D). One A animal, paralyzed by the convulsion (after displaying a clonic-only convulsion), was discarded and replaced by another $S$ of the same description.

The passive avoidance stepdown apparatus of Experiment 1 was used and FS and ECS parameters were unchanged.

On Days 11-13 all Ss received earclip adaptation in the home cage on the same schedule as in Experiment 1. On Day 14, the deprived Ss were found to weigh $235-290 \mathrm{~g}$ and the ad lib Ss weighed $320-375 \mathrm{~g}$. The remaining procedure of this study exactly followed that of Experiment 1 except that the duration of the tonic phase of each convulsion was measured with a stopwatch. Each animal received three pretraining trials and one FS + ECS training trial on Day 14.
Twenty-four hours later, all Ss were tested for retention.

\section{Results}

Twenty-nine of the $30 \mathrm{D}$ animals produced full tonic-clonic convulsions (DT) with hindlimb extension lasting a mean of $11 \mathrm{sec}$ (range: $4-15 \mathrm{sec}$ ). The one remaining $\mathrm{D}$ animal (DI) produced a tonic extension of hindlimbs at 90 deg to the body axis of 4-sec duration. Eighteen of the $30 \mathrm{~A}$ animals (AT) displayed full grand mal convulsions (this time defined as hindlegs at $135 \mathrm{deg}$ or more to the body axis) with hindlimb extension lasting a mean of $6 \mathrm{sec}$ (range $2-10 \mathrm{sec}$ ). The difference between 29 complete convulsions out of 30 deprived Ss and 18 out of $30 \mathrm{ad} \mathrm{lib}$ Ss was significant $\left(\chi^{2}=11.88, \mathrm{df}=1\right.$, $p<.005)$. Of the 12 remaining $A$ animals 10 produced clonic-only convulsions and two gave hindleg extensions at an angle approximating $30 \mathrm{deg}$ to the body axis and lasting for 4 and 5 sec. These 12 Ss were pooled in an "incomplete convulsion" group (AI) for further analysis. A $t$ test on duration of tonic extension among the full tonic-clonic animals found the $\mathrm{D}$ group tonic phase significantly longer than the $\mathbf{A}$ group $(\mathrm{t}=2.04, \mathrm{df}=45, \mathrm{p}<.05)$.

All $S$ s had stepdown latencies on the treatment trial of less than $12 \mathrm{sec}$. An overall $F$ test on these scores for the three groups with $\mathrm{n}>1$ (DT, AT, and AI) proved insignificant $(p>.30)$. However, analysis of these three groups found animals displaying different convulsive patterns did differ in performance on the retention trial $(F=6.02, \quad \mathrm{df}=2 / 56, \quad \mathrm{p}<.01)$. Median latencies for all four groups were DT $=13.8$, $\mathrm{AT}=20.1, \mathrm{AI}=58.2$, and $\mathrm{DI}$ (one animal) $=30.0 \mathrm{sec}$. Again all medians were consider ably less than medians of groups receiving FS without ECS in other studies using this apparatus (e.g., Lewis, Miller, \& Misanin, 1968) suggesting that all of the present groups displayed some degree of amnesia. A $t$ test between the two groups exhibiting tonic convulsions found that the retention scores of the deprived (DT) animals did not differ significantly from the ad lib (AT) animals $(p=.10)$. However, considering only ad lib Ss, those showing a complete convulsion (AT) had better retention scores than those displaying incomplete hindlimb extension $(A I)(t=2.78, d f=28, p<.01)$. Discussion

The present study provides evidence that food-deprived rats are more apt to display full tonic-clonic convulsions following ECS than are ad lib animals. Moreover, the tonic extension phase lasts longer in the deprived $S$ than in the fully convulsed ad lib $S$. No significant difference in the degree of amnesia was found between the two diets provided a complete convulsion occurred. However, less amnesia followed clonic-only convulsions than complete convulsions at least at the moderate ECS current level $(60 \mathrm{~mA})$ used in this study.

This analysis has adopted the position that retention test differences reflect differences in degree of amnesia. An alternative explanation is to hypothesize differences in initial learning as a function of diet or body weight and subsequent equal percentage losses through amnesia. We are inclined to reject this alternative on the basis of previous research in our laboratory that has found, after FS without ECS, no differences in retention over a wide range of weights $(140-320 \mathrm{~g})$ and deprivation conditions ( $5 \mathrm{~g} /$ day, ad lib) (at least within the limits of the 300-sec maximum latency on the test).

On the basis of the present data, it appears that Ss displaying partial convulsions after moderate ECS $(60 \mathrm{~mA}, .5 \mathrm{sec})$ also tend to yield attenuated amnesia. Moreover, animals maintained on a limited diet are more susceptible to both RA and complete convulsions. These findings are consistent with the proposition that convulsive pattern and degree of RA are correlated because both are functions of the current transversing the S's brain. Evidence that convulsive pattern and amnesia are not causally related comes from studies observing ECS-induced RA even when convulsions are pharmaceutically inhibited (e.g., McGaugh \& Alpern, 1966). Apparently some factor in addition to effective current influences the form of the convulsion, as high-intensity ECS ( $150 \mathrm{~mA})$ produces almost total RA but some Ss still fail to emit full convulsions (Weissman, 1964). If the effect of diet on amnesia and convulsive pattern is the result of differing amounts of extracranial tissue acting as a current shunt around the brain, then using either young animals or adults on weight-limiting diets should maximize the percentage of grand mal convulsions and degree of amnesia induced by constantcurrent ECS.

\section{REIERENCES}

HAYES, K. J. The current path in electric convulsive shock. Archives of Neurology \& Psychiatry, 1950, 63, 102-109.

JARVIK, M. E., \& KOPP, R. Transcorneal electroconvulsive shock and retrograde amnesia in mice. Journal of Comparative \& Phy siological Psychology, 1967, 64, 431-433.

LEWIS, D. J., MILLER, R. R., \& MISANIN, J. R. Control of retrograde amnesia. Journal of Comparative \& Physiological Psy chology, 1968, 66, 48-52.

MCDONALD, D. G. Ixperimental control of fractures produced by electroconvulsive shock. American Journal of Physiology, 1960, 199, 573-574.

McGAUGH, J. L., \& ALPERN, H. P. Effects of electroshock on memory: Amnesia without convulsions. Sciencc. 1966, 152, 665-666.

STERN, J. A., MCDONAL D, D. G., \& WERBOFF, J. Relationship between development of fractures during ICS, type of convulsion and weight of animals. American Joumal of Physiology, 1957, 189.381-383. 
WEISSMAN, A. Effect of electroconvulsive shock intensity and seizure pattern on retrograde amnesia in rats. Journal of Comparative \& Physiological Psychology, 1963, 56, 806-810.

WEISSMAN, A. Retrograde amnesia effect of supromaximal electroconvulsive shock on one-trial acquisition in rats. Journal of
Comparative \& Phy siological Psy chology, 1964, $57,248-250$

\section{NOTE}

1. This research was supported by National Institute of Mental Health Grant MH 12064. Gratitude is due Mr. Norman G. Richter for his technical assistance.

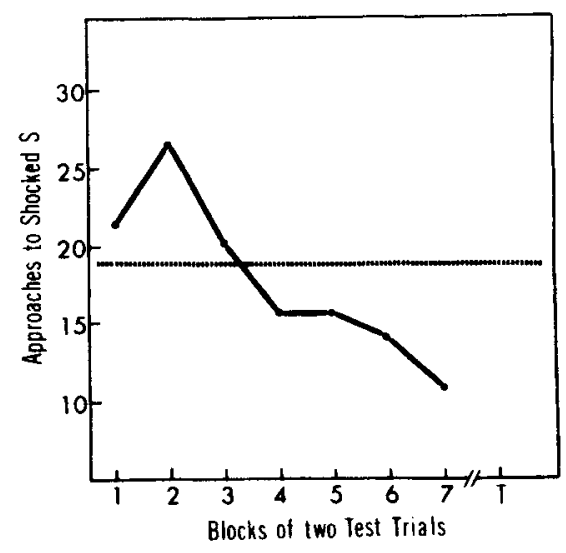

Fig. 1. Total number of "shocked" side choices for the last training day and for all testing days.

half of the Ss, a turn to the right activated a $0.5-\mathrm{mA}$ shock to the rat in the right end-box, and for the other half of the Ss, a turn to the left activated shock to the animal in the left end-box.

\section{RESULTS}

The apparatus consisted of a wooden $B R A U D$, University of Houston, Houston, Tex. 77004

Albino rats previously trained to run to sucrose reinforcers in both arms of a $T$ maze later avoided the arm which would result in shock to another rat.

In a study by Rice \& Gainer (1962), albino rats worked to terminate the distress of another rat: bar depression lowered a rat suspended in a harness. This aiding behavior was termed "altruistic" by the authors. Lavery \& Foley (1963) suggested that the Rice and Gainer results could be due to an increased activation effect due to arousal rather than to "altruism." In a follow-up study by Rice (1964), rats that were exposed to another rat being shocked did not press a bar to terminate the shock, and instead exhibited signs of fear. Wechkin, Masserman, \& Terris (1964), however, found that hungry rhesus monkeys would avoid chain-pulling for food when this meant shocking another monkey. They suggested that aversion to the perceived pain of conspecifics may have ethological survival value.

The present study was concerned with whe ther or not rats previously trained to run a $T$ maze for sucrose would avoid activating shock to another rat.

\section{SUBJECTS}

Twenty male Cheek-Jones albino rats, 150 days old, were assigned randomly to two groups of 10 Ss each. The Ss were caged individually, and were maintained at approximately $85 \%$ of their preexperimental body weight. They were allowed unlimited access to water.
$T$ maze, painted flat gray. The dimensions of the stem were $35 \times 5 \times 5 \frac{1}{2}$ in.; the arms were $22 \times 5 \times 5 \frac{1}{2} \mathrm{in}$. Attached to the end of each arm was an end-box, $8 \times 5 \times 51 / 2$ in. The floor of the end-box was constructed of $1 / 8$-in. stainless steel grid bars spaced $1 / 2$ in. center to center. The floor and top of the maze and the arm/end-box partition consisted of $1 / 4$-in. hardware cloth. The end-box tops were hinged, clear plastic lids. A goal cup (aluminum teaspoon) was placed at the end of each arm, centered on the arm/end-box partition $1 \frac{1}{2}$ in. above the floor. The rats' depression of a $6 \times 4$-in. wooden panel located on the floor of each arm, midway between the choice point and the goal cup, completed a circuit to the grid floor of each end-box. A SPDT slide switch determined which end-box grid was to be electrified by a fused, variable voltage autotransformer through a 10-K fixed resistor.

\section{PROCEDURE}

All Ss were given four training trials on each of 7 days, with 30 -min intertrial choice, which consisted of a run to either goal cup, which always contained $0.2 \mathrm{cc}$ of a $16 \%$ sucrose/distilled-water solution. To equate each rat's experience with the two arms of the maze, the second two daily trials were forced by closing one of the arms with a metal partition at the choice point. Both end-boxes contained a "victim" rat during all trials, and new "victim" rats were substituted every 10 trials.

All Ss were given four testing trials per day for 7 days, following the same procedure as during training, except that for intervals. The first two trials were free
Free choices were recorded for all $19 \mathrm{Ss}$ (one animal died at the beginning of training), during both the training and the of times the "shocked" side was chosen on the last day of training and on each of the 7 days of testing. Over all Ss, the percentage of choices of the shocked side dropped steadily from $58 \%$ at the beginning of testing to $31.5 \%$ at the end. A statistical comparison of the number of animals choosing the "shocked" side on the last training trial and on the last testing trial indicated that this decline was significant (chi square $=3.8$, $\mathrm{p}=.05)$.

\section{DISCUSSION}

Rats in a T maze tended to avoid running down the arm which would result in shock to another rat. There was a temporary increase in running to the shocked side noted on the second testing day which may have been due to the activation effect suggested by Lavery \& Foley (1963). The general trend, however, as in the Wechkin, Masserman, \& Terris (1964) study, was to avoid distressing a conspecific. In the Rice (1964) study, the rats were unable to avoid the shock onset and reacted with fear to the sight of another rat being shocked.

\section{REFERENCES}

LAVERY, J. J., \& FOLEY, P. J. Altruism or arousal in the rat? Science, 1963, 140, 172-173.

RICE, G. E. Aiding behavior vs fear in the albino rat. Psychological Record, 1964, 14, 165-170.

RICE, G. E., \& GAINER, P. "Aitruism" in the albino rat. Journal of Comparative \& Physiological Psychology, 1962, 55, 123-125.

WECHKIN, S., MASSERMAN, J. H., \& TERRIS, $W$. Shock to a conspecific as an aversive stimulus. Psychonomic Science, 1964, 1, 47-48. testing trials. Figure 1 presents the number 